\title{
Indoor air pollution associated with population health status
}

\section{DOI: $\underline{\text { http://doi.org/10.26758/8.1.19 }}$}

Elena Ciobanu (1), Cătălina Croitoru (1,3), Angela Cazacu-Stratu (2, 4), Serghei Cebanu (2, 4), Ovidiu Tafuni (1)

(1) State University of Medicine and Pharmacy "Nicolae Testemiţanu", Chisinau, Republic of Moldova, General Hygiene Department

(2) State University of Medicine and Pharmacy "Nicolae Testemiţanu", Chisinau, Republic of Moldova, Hygiene Department

(3) National Centre of Public Health, Chisinau, Republic of Moldova, Scientific Laboratory of Occupational Health

(4) National Centre of Public Health, Chisinau, Republic of Moldova, Teenager and Child Health Laboratory

Address correspondence to: Elena Ciobanu; Phone: +37379399610; E-mail: elena.ciobanu@usmf.md

\begin{abstract}
Objectives. The estimation of correlative connections between the harmful factors present on the premises, where meals are cooked and certain diseases of the respiratory system are conditioned by indoor air quality.

Material and methods. Three areas of the Republic of Moldova have been selected for research (North, Center, and South). 150 resident persons from the selected areas participated in the study, and they were invited to answer a series of questions. The air temperature, relative air humidity, and carbon dioxide were measured on the premises in which meals were cooked.

Results. The air pollution in kitchens correlates more essentially when using the bottled gas as fuel $(0.18 \leq \mathrm{r} \leq 0.44, \mathrm{p}<0.001)$ and has an influence of $37.5-41.5 \%$ as compared to natural gas. In case of cooking meals in the dwelling room using bottled gas, an average correlation was established with bronchitis $(\mathrm{r}=0.48, \mathrm{p}<0.01)$, pneumonia $(\mathrm{r}=0.56, \mathrm{p}<0.001)$, obstructive bronchitis $(\mathrm{r}=$ $0.54, \mathrm{p}<0.01)$ and very strongly with bronchial asthma $(\mathrm{r}=0.84, \mathrm{p}<0.01)$. In case of cooking meals in summer kitchens, the average correlation was recorded between the use of peasant stoves and the installation of bronchitis, pneumonia, obstructive bronchitis and a especially bronchial asthma.

Conclusion. The need is imposed to develop certain mechanisms of supervision of the indoor air quality. People responsible for the construction, furnishing and equipping the kitchens should fulfill certain rules that would not only relate to the architectural aesthetics, comfort or benefits implied, but also to the health of the people who will work on such premises with special destination.
\end{abstract}

Keywords: indoor air pollution, cooking, correlation coefficient, health status.

\section{Introduction}

The human beings can be affected by their own habitat. The World Health Organization (WHO) considers that approximately $30 \%$ of the dwelling premises present danger to human health. 
The exposure to polluted air leads to harmful effects on health, varying from respiratory diseases to chronic diseases, cancer, pregnancy complications, and premature death. Many studies show that the level of pollution of the indoor air positively correlates with the perceived health risks (Egondi et al., 2013; Leem et al., 2006; Simon et al., 2014; Uzoigwe et al., 2013).

According to the data presented by WHO (2014), more than $50 \%$ of the premature deaths caused by pneumonia in children under 5 years old are caused by the inhalation of particles polluting the air in households. Annually, between 3.3 and 4.3 million people prematurely die due to certain diseases relating to the pollution of air in households, as a result of cooking meals using solid fuel (Dickinson et al., 2015; Egondi et al., 2013; Simon et al., 2014; ***WHO, no.292, 2014). The biomass as fuel is largely recognized as an important source of pollution that affects human health, air quality at the local and regional level, and also has an impact on climate changes at the global level. All over the world, approximately three billion people use the biomass and coal as a fuel for cooking meals and heating the houses (***WHO, no.313, 2014). In rural areas, they often burn biomass in traditional stoves, with open fire, in low ventilated premises with smoke emissions. The released smoke contains high quantities of pollutants which have severe consequences for the health of the exposed persons. Women are involved in cooking meals and their small children pass the time together with them in such premises. Many studies have shown strong associations between burning biomass and increased incidence of chronic bronchitis in women and acute respiratory infections in children (Măruşteni 2006; Moshammer et al., 2010; Sharma et al., 1998). Significant connection with bronchial asthma, tuberculosis, low birth weight, cancer of the upper respiratory tract was also emphasized (Balakrishnan et al., 2004; WHO, no.292, 2014).

No such research was ever performed in the Republic of Moldova and the real situation concerning the discussed issue is not known. Although this topic was approached in the literature from the point of view of various physical factors and chemical substances, we have initiated our study from simple to complex, with clear perspectives of research for the future. This paper presents a wide evaluation of the conditions of cooking meals in the rural area of the Republic of Moldova and the analysis of the air in such premises in the presence of carbon dioxide and the variation of microclimate factors.

\section{Material and methods}

\section{Period and place of the research}

During the summer period of 2015, a poll was conducted in three areas of the Republic of Moldova (North, Center, and South), and certain physical parameters of the microclimate (temperature and relative humidity of the air) and chemical parameters (carbon dioxide) were measured in the premises were meals were cooked. The measurements were performed in the places where people were cooking meals: kitchens, dwelling premises, summer kitchens, with the aid of Air Quality Monitor 500 device. The stages of data collection were the following: before cooking meals (stage I of measurements), one hour after the beginning (stage II), at the end of the cooking (stage III), and one hour after the end (stage IV), during summertime. 11 questions were included in a questionnaire, and the answers were collected through the direct interview method. The questions referred to the place of cooking meals, types of fuel used by the population in the process of cooking meals, the complaints and suffered diseases. 


\section{Subjects and groups}

150 people were included in the study ( 50 persons from each of the North, Center, and South regions of the Republic of Moldova). Out of the total number of participants, $6 \%$ were men and $94 \%$ women, a fact explained by the national habits and traditions which assign to women the role of preparing the food for their family. In $99 \%$ of the cases, diseases of the respiratory system were found in the interviewed persons. The subjects were selected according to the following criteria: acceptance to participate in the study, age above 18 years old, responsibility and participation in the process of cooking meals.

\section{Methods applied}

A transversal study with analytic component was designed, using the following methods: observational, sociological, epidemiological and experimental.

\section{Statistical processing}

The results were analyzed by calculating intensive indices. The Student significant test was used for the specification of the degree of significance in comparing the mean values. The statistical connection between the factors was established using the correlation analysis. For determining the direction and strength of the relation between the studied indices, the Bravais-Pearson coefficient of simple and multiple linear correlations ( $r)$ and the determination coefficient $\left(r^{2}\right)$ were used. The correlation coefficient measures the degree of proximity of the linear association between two variables, and the determination coefficient shows the proportion of variability in the model for the dependent variable. The degree of statistical significance of the correlation was established based on ANOVA test in the Statgraphics Plus 2.1 software. The ANOVA test measures whether a factor contributes significantly to the variation of the answer and determines the extent of variation which is due to a pure error. If the $p$-value in the ANOVA table is $0.05-0.001$, we may affirm that there is a statistically significant connection between the variables at a confidence level of $95.0-99.9 \%$.

\section{Results}

In case of the households where people complained of bronchitis and obstructive bronchitis, the mean values of the temperature (Table 1) for the three types of premises showed the following pattern: after one hour from the beginning of the cooking process (stage II), the air temperature increased by $1.8^{\circ} \mathrm{C}$ as compared to the beginning moment (stage I), and, at the end of cooking (stage III), the temperature increased by $3.6^{\circ} \mathrm{C}$ as compared to stage I. After one hour from the moment of finishing the cooking process (stage IV), the air temperature was higher by $0.7^{\circ} \mathrm{C}$ as compared to stage I.

In the premises in which people suffering from pneumonia were cookeding meals, the mean temperature of the air (the mean value in the three types of premises) increased by $2.0^{\circ} \mathrm{C}$ one hour from the starting moment of the cooking process (stage II) as compared to the initial value (stage I), and, at the end (stage III), the air temperature increased by $5.5^{\circ} \mathrm{C}$ as compared to stage I. One hour after (stage IV), the air temperature was higher by $3.3^{\circ} \mathrm{C}$ as compared to stage I.

The air temperature in the premises where people suffering from bronchial asthma were cooking meals increased by $5.6^{\circ} \mathrm{C}$ in the first hour (stage II) and by $5.5^{\circ} \mathrm{C}$ at the end of the process (stage III) as compared to stage I. One hour after the cooking (stage IV), the air temperature was higher by $1.8^{\circ} \mathrm{C}$ as compared to stage $\mathrm{I}$.

In all the analyzed cases, the air temperature one hour after the end of the cooking process did not return to the initial level, as it was recorded. 
Table 1. Values of air temperature, ${ }^{\circ} \mathrm{C}$

\begin{tabular}{|l|l|c|c|c|c|}
\hline \multicolumn{2}{|c|}{} & Stage I & Stage II & Stage III & Stage IV \\
\hline \multirow{2}{*}{$\begin{array}{l}\text { Bronchitis } \\
\text { and } \\
\text { obstructive } \\
\text { bronchitis }\end{array}$} & kitchen & 27.5 & 29.1 & 31.1 & 28.9 \\
\cline { 2 - 5 } & dwelling room & 26.8 & 29.1 & 30.7 & 27.8 \\
\cline { 2 - 5 } & summer kitchen & 28.5 & 29.9 & 31.9 & 28.1 \\
\cline { 2 - 5 } & average & $27.6 \pm 0.49$ & $29.4 \pm 0.27$ & $31.2 \pm 0.35$ & $28.3 \pm 0.33$ \\
\hline \multirow{4}{*}{\begin{tabular}{l} 
Pneumonia \\
\cline { 2 - 5 }
\end{tabular}} & kitchen & 28.6 & 31.4 & 37.9 & 34.4 \\
\cline { 2 - 5 } & dwelling room & 28.2 & 29.7 & 31.3 & 30.1 \\
\cline { 2 - 5 } & aummer kitchen & 28.1 & 29.7 & 32.1 & 30.3 \\
\hline \multirow{4}{*}{ Asthma } & kitchen & $28.3 \pm 0.15$ & $30.3 \pm 0.57$ & $33.8 \pm 2.08$ & $31.6 \pm 1.40$ \\
\cline { 2 - 6 } & dwelling room & 27.8 & 30.7 & 33.4 & 29.8 \\
\cline { 2 - 6 } & summer kitchen & 28.6 & 39.3 & 34.8 & 29.9 \\
\cline { 2 - 6 } & average & $27.8 \pm 0.46$ & $33.4 \pm 2.94$ & $33.3 \pm 0.93$ & $29.6 \pm 0.22$ \\
\hline
\end{tabular}

The value of the relative humidity of the air, in the premises where people suffering from bronchitis and obstructive bronchitis were cooking meals (Table 2), had the same dynamics as the air temperature: one hour from the beginning (stage II), it increased by $1.8 \%$, at the end (stage III) by $3.5 \%$, and one hour after (stage IV) by $0.7 \%$ as compared to stage I.

In the premises in which people frequently suffering from pneumonia were cooking meals, the relative humidity (the average of recorded values) increased by $5 \%$ one hour after starting the cooking process (stage II), and by $12.7 \%$ at the end of the process (stage III) as compared to stage I. The relative humidity was higher by $7.0 \%$ one hour after the end (stage IV) as compared to the beginning of the cooking.

In the premises where people complaining of bronchial asthma were cooking meals, the relative humidity of the air increased in the first hour (stage II) by $1.7 \%$ and by $4.8 \%$ at the end (stage III) as compared to stage I. One hour after finishing the cooking process (stage IV), the relative humidity of the air was higher by $2.5 \%$ as compared to the beginning moment.

In all the analyzed cases, the relative humidity of the air one hour after finishing meal cooking has not exceeded the normed level.

Table 2. Values of the relative humidity of the air, \%

\begin{tabular}{|c|c|c|c|c|c|}
\hline & Stage I & Stage II & Stage III & Stage IV \\
\hline \multirow{4}{*}{$\begin{array}{l}\text { Bronchitis } \\
\text { and } \\
\text { obstructive } \\
\text { bronchitis }\end{array}$} & kitchen & 49.5 & 50.6 & 52.9 & 50.6 \\
\hline & dwelling room & 50.2 & 52.7 & 53.5 & 53.5 \\
\hline & summer kitchen & 47.7 & 49.4 & 51.4 & 45.2 \\
\hline & average & $49.1 \pm 0.74$ & $50.9 \pm 0.96$ & $52.6 \pm 0.62$ & $49.8 \pm 2.43$ \\
\hline \multirow{4}{*}{ Pneumonias } & kitchen & 49.2 & 57.6 & 69.7 & 63.4 \\
\hline & dwelling room & 48.4 & 53.4 & 60.3 & 52.3 \\
\hline & summer kitchen & 47.7 & 49.2 & 53.3 & 50.4 \\
\hline & average & $48.4 \pm 0.43$ & $53.4 \pm 2.42$ & $61.1 \pm 4.75$ & $55.4 \pm 4.05$ \\
\hline \multirow{4}{*}{ Asthma } & kitchen & 48.1 & 49.8 & 52.0 & 49.1 \\
\hline & dwelling room & 48.1 & 51.0 & 55.7 & 52.8 \\
\hline & summer kitchen & 48.0 & 48.6 & 50.9 & 49.9 \\
\hline & average & $48.1 \pm 0.03$ & $49.8 \pm 0.69$ & $52.9 \pm 1.45$ & $50.6 \pm 1.12$ \\
\hline
\end{tabular}


In the premises where people suffering from bronchitis and obstructive bronchitis were cooking meals, the average of values of the carbon dioxide concentration showed the following pattern (Table 3): the concentration of carbon dioxide increased in stage II by $0.1 \%$ and by $0.2 \%$ in stage III as compared to stage I. And one hour after finishing the process, it returned to the value of $0.1 \%$.

In the premises in which people frequently suffering from pneumonia were cooking meals, the concentration of carbon dioxide (the mean value for all three types of premises) increased by $0.1 \%$ in stage II and at the end of the cooking process the concentration of carbon dioxide increased by $0.2 \%$ as compared to stage I. One hour after the end, the concentration of carbon dioxide returned to the value of $0.1 \%$.

In the premises in which people suffering from bronchial asthma were cooking meals, the mean values of carbon dioxide increased by $0.1 \%$ one hour after the beginning (stage II) and by $0.2 \%$ at the end of the process (stage III) as compared to stage I. One hour after the finishing moment, the mean value of carbon dioxide concentration was higher by $0.1 \%$ as compared to stage I.

The analysis of the mean values of carbon dioxide concentration in the premises in which the meals were cooked, highlights the fact that the monitored values returned to the initial level and did not exceed the normed levels, except those in which people suffering from bronchial asthma were cooking meals, where the mean value of carbon dioxide concentration was higher than the initial value and exceeded the normed value by $0.1 \%$.

Table 3. Values of carbon dioxide, $\%$

\begin{tabular}{|l|l|c|c|c|c|}
\hline \multicolumn{2}{|c|}{} & Stage I & Stage II & Stage III & Stage IV \\
\hline \multirow{3}{*}{$\begin{array}{l}\text { Bronchitis } \\
\text { and } \\
\text { obstructive } \\
\text { bronchitis }\end{array}$} & kitchen & 0.1 & 0.2 & 0.2 & 0.1 \\
\cline { 2 - 6 } & dwelling room & 0.1 & 0.2 & 0.3 & 0.1 \\
\cline { 2 - 6 } & summer kitchen & 0.1 & 0.2 & 0.3 & 0.1 \\
\cline { 2 - 5 } & average & 0.1 & 0.2 & $0.3 \pm 0.03$ & 0.1 \\
\cline { 2 - 6 } Pneumonias & kitchen & 0.1 & 0.1 & 0.3 & 0.1 \\
\cline { 2 - 6 } & dwelling room & 0.1 & 0.3 & 0.5 & 0.2 \\
\cline { 2 - 6 } & summer kitchen & 0.1 & 0.1 & 0.3 & 0.1 \\
\cline { 2 - 6 } & average & 0.1 & $0.2 \pm 0.07$ & $0.4 \pm 0.07$ & $0.1 \pm 0.03$ \\
\hline \multirow{4}{*}{ Asthma } & kitchen & 0.1 & 0.1 & 0.1 & 0.1 \\
\cline { 2 - 6 } & dwelling room & 0.1 & 0.3 & 0.4 & 0.3 \\
\cline { 2 - 6 } & summer kitchen & 0.1 & 0.1 & 0.4 & 0.1 \\
\cline { 2 - 6 } & average & 0.1 & $0.2 \pm 0.07$ & $0.3 \pm 0.10$ & $0.2 \pm 0.07$ \\
\hline
\end{tabular}

The performed research showed that the indoor air is more polluted in case of cooking meals in the dwelling premises, influencing thus the health status of the dwellers. It was found that in the events when the population had premises specially equipped as kitchens - the cooking conditions were not favorable because these did not fully correspond to the requirements. When cooking meals in summer kitchens, the physical and chemical parameters of the air were relatively closer to the normed values. The values of the researched parameters also depend on the type of cooking installation and the fuel used by the population. The research showed that the air was more polluted when traditional stoves were used. The bottled gas used for cookers polluted the air more than the natural gas. Among the types of fuel used for traditional stoves, some crop residues and the biomass polluted the air the most. 
The pollution of air in kitchens, in case of cooking on cooker, slightly but significantly correlates with the onset of bronchitis $(\mathrm{r}=0.19, \mathrm{p}<0.001)$ and pneumonia $(\mathrm{r}=0.37, \mathrm{p}<0.001)$, while moderately correlates with the onset of obstructive bronchitis and bronchial asthma $(0.48 \leq \mathrm{r} \leq$ $0.57, \mathrm{p}<0.01)$. This factor has an influence of $22.0-31.1 \%$. A more essential correlation was recorded when bottled gas was used as fuel $(0.18 \leq \mathrm{r} \leq 0.44, \mathrm{p}<0.001)$ and an influence of 37.5 $41.5 \%$, which is higher as compared to the use of natural gas $\left(0.12 \leq \mathrm{r} \leq 0.45, \mathrm{p}<0.001 ; 21.5 \leq \mathrm{r}^{2} \leq\right.$ 28.7). Due to the incorrect and insufficient ventilation, significant increases of temperature and relative humidity of the air were recorded during meal cooking, and the measurements one hour after finishing the cooking process showed that the values of such parameters did not return to the norm in most of the cases. The absence of ventilation strongly correlates with all nosologic forms mentioned by the respondents $(0.73 \leq \mathrm{r} \leq 0.96, \mathrm{p}<0.01)$ and influences the onset of diseases to the extent of $34.6 \%$.

In the case of cooking inside the dwelling room, a slight correlation with all the nosologic forms was recorded both when cooking on cooker $(0.22 \leq \mathrm{r} \leq 0.31, \mathrm{p}<0.01)$ and on traditional stove $(0.31 \leq \mathrm{r} \leq 0.38, \mathrm{p}<0.001)$. Cooking on cooker has a rate of influence of $27.6 \%$ while cooking on a stove of $38.4 \%$ on the development of diseases of which the respondents suffer from. The use of bottled gas during cooking on cooker has an average correlation with bronchitis $(\mathrm{r}=0.48, \mathrm{p}<0.01)$, pneumonia $(r=0.56, p<0.001)$, obstructive bronchitis $(r=0.54, p<0.01)$, and a strong correlation with bronchial asthma $(\mathrm{r}=0.84, \mathrm{p}<0.01)$, while the use of natural gas shows a low correlation $(0.12$ $\leq \mathrm{r} \leq 0.22, \mathrm{p}<0.01)$. When the population used wood as fuel for the peasant stove, a slight correlation was recorded with bronchitis $(\mathrm{r}=0.31, \mathrm{p}<0.001)$, pneumonia $(\mathrm{r}=0.35, \mathrm{p}<0.05)$, and an average correlation with obstructive bronchitis $(\mathrm{r}=0.52, \mathrm{p}<0.01)$ and bronchial asthma $(\mathrm{r}=$ $0.63, \mathrm{p}<0.01)$. All the researched nosological forms have proven an average correlation with the use of the biomass $(0.49 \leq \mathrm{r} \leq 0.66, \mathrm{p}<0.001)$ and crop residues $(0.44 \leq \mathrm{r} \leq 0.58, \mathrm{p}<0.001)$. Out of all the types of fuel used by the population for cooking, the highest share of influence is held by the crop residues $\left(r^{2}=48.4\right)$ and biomass $\left(r^{2}=45.0\right)$, a lower influence being held by the faggots $\left(r^{2}=\right.$ $37.6 \%)$ and bottled gas $\left(r^{2}=35.3\right)$, while the lowest share by the wood $\left(r^{2}=27.6\right)$ and natural gas $\left(r^{2}\right.$ $=22.4)$. The absence of an adequate ventilation system slightly but significantly correlates with the onset of bronchitis $(r=0.32, p<0.001)$, pneumonia $(r=0.29, \mathrm{p}<0.001)$, obstructive bronchitis $(\mathrm{r}=$ $0.37, \mathrm{p}<0.001)$ and strongly correlates with the installation of the bronchial asthma $(\mathrm{r}=0.88, \mathrm{p}<$ $0.001)$.

In the summer kitchens, the cooking process recorded a lower correlation with the pollution-induced diseases as compared to the cooking in the dwelling room. At the same time, as most of the premises have no windows, the pollution of air is maintained by a low ventilation.

For the cooking process, the population uses the cooker/natural gas stove, the traditional stove/cook stove and/or the electrical cooker. Cooking the meals on the cooker slightly correlates with the bronchitis $(\mathrm{r}=0.22, \mathrm{p}<0.05)$, pneumonia $(\mathrm{r}=0.26, \mathrm{p}<0.01)$, obstructive bronchitis $(\mathrm{r}=$ $0.31, \mathrm{p}<0.001)$, and bronchial asthma $(\mathrm{r}=0.25, \mathrm{p}<0.001)$. Moderate correlation was recorded between the use of traditional stoves and the onset of bronchitis $(r=0.44, p<0.001)$, pneumonia $(r$ $=0.49, \mathrm{p}<0.01)$, and obstructive bronchitis $(\mathrm{r}=0.65, \mathrm{p}<0.001)$, while strong correlation between it and bronchial asthma $(\mathrm{r}=0.84, \mathrm{p}<0.001)$. Cooking on the cooker influenced the development of diseases to the extent of $23.4 \%$, while cooking on a traditional stove at the extent of $29.7 \%$.

Wood, raw and processed coal, natural gas supplied through centralized pipeline or bottled gas, biomass, crop residues, etc. are used as fuel. The research showed a strong correlation $(0.74 \leq \mathrm{r}$ $\leq 0.80, \mathrm{p}<0.01)$ when using bottled gas, with a share of influence of $38.0 \%$ and a slight correlation when using natural gas $(0.11 \leq \mathrm{r} \leq 0.34, \mathrm{p}<0.001)$ with a share of influence $23.6 \%$. The use of wood and faggots moderately correlates with obstructive bronchitis $\left(r=0.63, p<0.01 ; r^{2}=31.4\right)$ and 
bronchial asthma $\left(\mathrm{r}=0.54, \mathrm{p}<0.001 ; \mathrm{r}^{2}=43.6\right)$. The use of agricultural waste has an average correlation with bronchitis $\left(r=0.63, p<0.01 ; r^{2}=46.1\right)$, pneumonia $\left(r=0.59, p<0.001 ; r^{2}=36.1\right)$, obstructive bronchitis $\left(r=0.64, p<0.001 ; r^{2}=39.2\right)$ and strongly correlates with bronchial asthma $\left(\mathrm{r}=0.90, \mathrm{p}<0.01 ; \mathrm{r}^{2}=42.3\right)$. The insufficient ventilation in these premises slightly correlates with bronchitis $(\mathrm{r}=0.28, \mathrm{p}<0.001)$ and pneumonia $(\mathrm{r}=0.33, \mathrm{p}<0.05)$, while it has an average correlation with obstructive bronchitis $(r=0.47, \mathrm{p}<0.01)$ and strongly correlates with bronchial asthma $(r=0.91, p<0.01)$. This factor influences the development of the mentioned diseases to the extent of $37.6-45.9 \%$.

An important aspect in the indoor pollution is the area of premises. The area inversely correlates with air pollution and development of diseases. A moderate correlation was recorded between the area of premises and bronchitis $S(r=0.58, p<0.05)$, pneumonia $(r=0.45, p<0.01)$ and obstructive bronchitis $(\mathrm{r}=0.52, \mathrm{p}<0.001)$, and a strong correlation with bronchial asthma $(\mathrm{r}=$ $0.85, \mathrm{p}<0.001)$.

Very important in the development of diseases is the duration and frequency of the cooking process. A slight direct correlative connection was established with bronchitis $(\mathrm{r}=0.18, \mathrm{p}<0.001)$, a strong correlation with pneumonia $(\mathrm{r}=0.74, \mathrm{p}<0.01)$, obstructive bronchitis $(\mathrm{r}=0.87, \mathrm{p}<0.01)$, and bronchial asthma $(\mathrm{r}=0.84, \mathrm{p}<0.01)$. The correlation between the frequency of meal cooking and nosological forms was moderate $(0.38 \leq \mathrm{r} \leq 0.63, \mathrm{p}<0.05)$. The duration of the cooking process explains approximately $18.4 \%$ of the variability of nosological forms.

The smokers are exposed to additional pollutants. The fact that people smoke presents a slight correlative connection with the development of pneumonia $(\mathrm{r}=0.26, \mathrm{p}<0.05)$, a moderate correlation with bronchitis $(\mathrm{r}=0.42, \mathrm{p}<0.001)$ and obstructive bronchitis $(\mathrm{r}=0.51, \mathrm{p}<0.01)$, and a strong correlation with bronchial asthma $(\mathrm{r}=0.83, \mathrm{p}<0.001)$. The number of cigarettes smoked per day strongly and directly correlates with the nosological forms present in the respondents $(0.76 \leq \mathrm{r} \leq$ $0.89, \mathrm{p}<0.01)$.

The diseases of the respiratory system strongly correlate with the relatively increased humidity of the air $(0.78 \leq \mathrm{r} \leq 0.94, \mathrm{p}<0.001)$ and concentration of carbon dioxide $(0.70 \leq \mathrm{r} \leq 0.82$, $\mathrm{p}<0.01)$ and moderately correlate with the air temperature $(0.43 \leq \mathrm{r} \leq 0.68, \mathrm{p}<0.001$. The modifications of the relative humidity of the air and of the concentration of carbon dioxide explain approximately $30.6 \%$ and respectively $34.5 \%$ of the variability of respiratory diseases.

For assessing the complex influences of the cooking conditions, multiple correlation analysis was applied, taking into consideration the following factors: type of premises, the area of premises, type of installation and type of fuel. The multiple influences explain $61.3-76.6 \%$ (p< 0.01) of action of the above factors in the development of the nosological forms recorded in the respondents. The combined influences of insufficient ventilation and indoor smoking are responsible for up to $57.3 \%$ of the population health problems ( $<<0.05)$. Researching the complex action of the physical and chemical factors, created during the cooking process, on the mentioned diseases, a statistically significant $(\mathrm{p}<0.001)$ coefficient of determination was established $(62.3-76.1 \%)$.

\section{Discussions}

In the opinion of Moshammer et al. (2010), the problem of emissions resulting from burning bottled gas, biomass and other types of fuel used in the household for meal cooking is not enough studied. The emissions from the cooker create conditions of air pollution inside the premises, directly contributing to the pollution due to the inefficient ventilation system (exchange of air between indoors and outdoors), and the lack of means and technologies for the elimination of the polluted air outside. According to the research performed by Balakrishnan et al. (2002) and Bruce et 
al. (2000), the products of burning gas and biomass ejected directly in the interior environment increase the concentration of various substances in the air, which negatively affects the health of people participating in the cooking process. Currently, the studies performed in this direction are of interest to the public health and it is worth continuing them in various countries with different levels of development. The analysis of various substances in kitchens is necessary for the evaluation of their impact on population health and the effective reduction of morbidity and mortality from pollution-induced diseases.

The study performed by a group of researchers from California, USA, (Logueet al., 2014), proved that the use of cooking installations fueled with natural gas without vapor hoods for the aspiration of the polluted air directly influences the health status of the resident people and increase the concentration of harmful chemical substances, such as $\mathrm{CO}, \mathrm{NO}_{2}$ as compared to the standardized values for the atmosphere air in $55-70 \%$ and $7-8 \%$ of houses during one typical week in winter.

Our research emphasizes the impact of gas emissions in kitchens not only on the health of adult people involved in the process of cooking meals but also on children who, for various reasons, are present in such premises. Such studies were also carried out by Marks et al. (2010) in Australia, where, in the classrooms equipped with gas cookers, children complained of cough intensification in the morning and during the day, and inflammation of the respiratory tract was noticed in children suffering from bronchial asthma.

As we have already mentioned in the "Materials and methods" section, comparative analysis has been performed between various types of fuel used for the purpose of cooking meals and cooking installations, as well as their degree of technical failure. The degree of gas use was higher as compared to other fuels, for example to biomass. Some studies, such as those performed by Mutlu et al. (2016), showed that there is a strong correlation between the type of fuel used (in that case, wood) and the mutagenic factors.

Consequently, all the people, including healthy adults, could suffer from respiratory diseases caused by the loss of pulmonary function, development of bronchitis, bronchial asthma, etc., till the onset of chronic pulmonary diseases, because the impact of the exposure may have a cumulative effect in time.

According to the research performed by Lupulescu et al. (2008), the sources of air pollution in dwelling premises are relatively numerous and may be classified as permanent, temporary, and accidental. The over-agglomeration and increased humidity in the dwelling premises represent aggravating factors for the onset of dampness and development of fungus, as well as the increased frequency of some respiratory tract diseases, allergic diseases, etc.

The study performed on a sample of 2123 people from 830 dwelling houses in Romania had the purpose of evaluating the dwelling conditions and state of health. The research proved that the non-corresponding thermal environment is a favorable factor in the onset of the condensate and mold, and also a risk factor in the onset of recurrent infections, especially in children. These conditions are associated with the decrease of ventilation in the dwelling premises, including kitchens, in order to increase the energy efficiency. Special attention was paid to the parents' habit of smoking in the housing premises, which is an important risk factor for bronchial asthma in children, since blood eosinophilia and a higher total serum immunoglobulin $\mathrm{E}$ ( $\mathrm{IgE}$ ) level is associated with smoking. The frequency of respiratory tract infections is higher in these children.

To a great extent, the same objectives were also followed by Dasgupta et al. (2013) from Madagascar. A regression analysis was performed to investigate the basic determinant factors, such as various types of fuel (coal, wood, ethanol), ovens (traditional, improved), dimension of the kitchen, type of kitchen (opened, ventilated), construction materials for the kitchen (permeable roof and walls) and environmental factors. The results show that the type of fuel, types of cooker, and the 
kitchen dimension play an important role in the onset of various diseases. In comparison, the air quality is better in case of using ethanol than biomass. Finally, a large kitchen and adequate ventilation in the cooking areas will produce a healthier environment and decrease harmful emissions.

Another study, performed by Sussan et al. (2014) in India shows that the use of the biomass (wood, dung) could increase the risk of chronic respiratory diseases by activating the TLR and IL$1 \mathrm{R}$ receptors (experiment on mice).

In the context of fundamental research concerns towards the actions of the atmosphere pollutants on the nervous system, the scientists from the Center for Research in Environmental Epidemiology (CREE), Barcelona, Spain (2012), studied the relation between the pollutants emanated in the indoor air from the cooker and the development of neural diseases in children and pregnant women. This study emphasizes a decreased adverse effect of indoor air pollution from the cooker on the mental development of small children, the cooker being considered the main source of pollution of the indoor air, including nitrogen dioxide and emanated particles (Vrijheid et al., 2012).

\section{Conclusions}

In light of the above, it is necessary to develop some mechanisms for controlling indoor air quality.

The people responsible for the construction, furnishing and equipping the kitchens should meet certain rules which would not only relate to the architectural aesthetics, comfort or carried benefits, but also to the health of those who will work in such premises with special destination.

The cooking process should be performed in optimal sanitary-hygienic conditions, under rigorous surveillance of the personal hygiene rules and safety requirements, which involves the installation and maximal use of the artificial ventilation installations, for example vapor hoods, aspiration ventilators, etc.; the replacement of some types of fuel (biomass, coal etc.) by natural gas, which is less toxic.

Acknowledgment. The research reported in this publication was supported by the Fogarty International Center of the National Institutes of Health under Award Number R24TW009568. The content is solely the responsibility of the authors and does not necessarily represent the official views of the National Institutes of Health.

Conflict of interest. The authors of this article do not have any conflict of interests.

\section{References}

1. Balakrishnan, K., Mehta, S., Kumar, P., Ramaswamy, P., Sambandam, S., Kumar, K. and Smith, K., 2004. Indoor Air Pollution Associated with Household Fuel Use in India: An exposure assessment and modeling exercise in rural districts of Andhra Pradesh, India. Washington DC, USA: The International Bank for Reconstruction and Development/The World Bank.

2. Balakrishnan, K., Sankar, S., Parikh, J., Padmavathi, R., Srividya, K., Venugopal, V., Prasad, S. and Pandey, V., 2002. Daily average exposures to respirable particulate matter from combustion of biomass fuels in rural households of southern India. Environ. Health Perspect, 110(11), p.1069. 
3. Bates, M., Ram, K. Chandyo, R., Valentiner-Branth,P., Pokhrel, A., Mathisen, M., Basnet, S., Shrestha, P., Strand, T. and Smith, K., 2013. Acute Lower Respiratory Infection in Childhood and Household Fuel Use in Bhaktapur, Nepal. Environmental Health Perspectives, 121(5), pp.637-642.

4. Bruce, N., Perez-Padilla, R. and Albalak, R., 2000. Indoor air pollution in developing countries: a major environmental and public health challenge. Bull. World Health Organ, 78(9), pp.10781092.

5. Dasgupta, S., Martin, P. \& Samad, H., 2013. Addressing household air pollution: a case study in rural Madagascar. The World Bank, Africa Region, Sustainable Development Department \& Development Research Group, Environment and Energy Team. Available at: <http://wwwwds.worldbank.org/external/default/WDSContentServer/IW3P/IB/2013/10/09/000158349_2013 1009092916/Rendered/PDF/WPS6627.pdf. > [Accessed 4 May 2017].

6. Dickinson, K., Kanyomse, E., Piedrahita, R., Coffey, E., Rivera, I., Adoctor, J., Alirigia, R., Muvandimwe, D., Dove, M., Dukic, V., Hayden, M., Diaz-Sanchez, D., Abisiba, A., Anaseba, D., Hagar, Y., Masson, N., Monaghan, A., Titiati, A., Steinhoff, D., Hsu, Y., Kaspar, R., Brooks, B., Hodgson, A., Hannigan, M., Oduro, A. R. and Wiedinmyer, Ch., 2015. Research on Emissions, Air quality, Climate, and Cooking Technologies in Northern Ghana (REACCTING): study rationale and protocol. BMC Public Health, 15:126, https://doi.org/10.1186/s12889-0151414-1.

7. Egondi, T., Kyobutungi, C., Ng, N., Muindi, K., Oti, S., Vijver, S., Ettarh, R. \& Rocklöv, J., 2013. Community Perceptions of Air Pollution and Related Health Risks in Nairobi Slums. $J$ Environ Res Public Health, 10(10), pp.4851-4868.

8. Leem, J., Kaplan, B., Shim, Y., Pohl, H., Gotway, C., Bullard, S., Rogers, J., Smith, M. \& Tylenda, C., 2006. Exposures to Air Pollutants during Pregnancy and Preterm Delivery. Environmental Health Perspectives, 114(6), pp.905-910.

9. Logue, J., Klepeis, N., Lobscheid, A. \& Brett, C., 2014. Pollutant Exposures from Natural Gas Cooking Burners: A Simulation-Based Assessment for Southern California. Environmental Health Perspectives, 122(1), pp.43-50.

10. Lupulescu, D., Fulga, M. \& Iancu, M., 2008. Factori alergizanţi prezenţi în mediul de locuit. [Allergic factors present in the living environment] Revista de Igienă şi Sănătate Publică, 58(1), pp.22-28.

11. Marks, G., Ezz, W., Aust, N., Toelle, B., Xuan, W., Belousova, E., Cosgrove, C., Jalaludin, B. \& Wayne, T., 2010. Smith Respiratory Health Effects of Exposure to Low-NOx Unflued Gas Heaters in the Classroom: A Double-Blind, Cluster-Randomized, Crossover Study. Environmental Health Perspectives, 118, pp.1476-1482.

12. Mărușteni, M., 2006. Noţiuni fundamentale de biostatistică: note de curs [Fundamental notions of Biostatistics: Course Notes]. Târgu-Mureş: University Press.

13. Moshammer, H., Fletcher, T., Heinrich, J., Hoek, G., Hruba, F. \& Pattenden, S., 2010. Gas cooking is associated with small reductions in lung function in children. European Respiratory Journal, 36(2), pp.249-254.

14. Mutlu, E., Warren, S., Ebersviller, S., Kooter, I., Schmid, J., Dye, J., Linak, W., Gilmour, I., Jetter, J., Higuchi, M. \& DeMarini, D., 2016. Mutagenicity and Pollutant Emission Factors of Solid-Fuel Cookstoves: Comparison with Other Combustion Sources. Environmental Health Perspectives, 124(7), pp.974-982.

15. Sharma, S., Sethi, G., Rohtagi, A., Chaudhary, A., Shankar, R. \& Bapna, J., 1998. Indoor air quality and acute lower respiratory infection in Indian urban slums. Environmental Health Perspectives, 106, pp.291-297. 
16. Simon, G., Bailis, R., Baumgartner, J., Hyman, J. \& Laurent, A., 2014. Current debates and future research needs in the clean cookstove sector. Energy for Sustainable Development, 20, pp.49-57.

17. Sussan, T., Ingole, V., Kim, J., McCormick, S., Negherbon, J., Fallica, J., Akulian, J., Yarmus, L., Feller-Kopman, D., Wills-Karp, M., Horton, M., Breysse, P., Agrawal, A., Juvekar, S., Salvi, S. \& Biswal, S., 2014. Source of biomass cooking fuel determines pulmonary response to household air pollution. American Journal of Respiratory Cell and Molecular Biology, 50(3), pp.538-548.

18. Uzoigwe, J., Prum, T., Bresnahan, E. \& Garelnabi, M., 2013. The Emerging Role of Outdoor and Indoor Air Pollution in Cardiovascular Disease. North American Journal of Medicine \& Science, 5(8), pp.445-453.

19. Vrijheid, M., Martinez, D., Aguilera, I., Bustamante, M., Ballester, F., Estarlich, M., FernandezSomoano, A., Guxens, M., Lertxundi, N., Martinez, M., Tardon, A. \& Sunyer, J., 2012. Indoor air pollution from gas cooking and infant neurodevelopment. Epidemiology, 23(1), pp.23-32.

20. ***WHO, 2014. Ambient (outdoor) air quality and health. Fact sheet N313. Available at: <http://www.who.int/mediacentre/factsheets/fs313/en/. > [Accessed 10 May 2017].

21. ***WHO, 2014. Household air pollution and health. Fact sheet N292, 2014. Available at: <http://www.who.int/mediacentre/factsheets/fs292/en/.> [Accessed 10 May 2017]. 